\title{
Automatic recognition of lactating sow behaviors through depth image processing
}

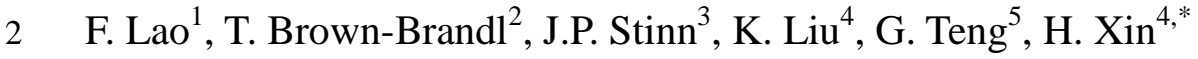

$3 \quad{ }^{I}$ Network Center, China Agricultural University, Beijing, China, laofd@cau.edu.cn

$4 \quad{ }^{2}$ USDA-ARS Meat Animal Research Center, Clay Center, NE, USA

$5 \quad{ }^{3}$ Iowa Select Farms, Iowa Falls, IA, USA

$6 \quad{ }^{4}$ Department of Agricultural and Biosystems Engineering, Iowa State University, Ames, IA, USA

$7 \quad{ }^{5}$ College of Water Resources \& Civil Engineering, China Agricultural University, Beijing, China

$8 \quad *$ Corresponding author: hxin@iastate.edu

9 Abstract

Manual observation and classification of animal behaviors is laborious, time-consuming, and of limited ability to process large amount of data. A computer vision-based system was developed that automatically recognizes sow behaviors (lying, sitting, standing, kneeling,

13 feeding, drinking, and shifting) in farrowing crate. The system consisted of a low-cost 3D camera that simultaneously acquires digital and depth images and a software program that detects and identifies the sow's behaviors. This paper describes the computational algorithm for the analysis of depth images and presents its performance in recognizing the sow's behaviors as compared to manual recognition. The images were acquired at $6 \mathrm{~s}$ intervals on three days of a 21-day lactation

18 period. Based on analysis of the $6 \mathrm{~s}$ interval images, the algorithm had the following accuracy of behavioral classification: $99.9 \%$ in lying, $96.4 \%$ in sitting, $99.2 \%$ in standing, $78.1 \%$ in kneeling, 97.4\% in feeding, $92.7 \%$ in drinking, and $63.9 \%$ in transitioning between behaviors. The lower classification accuracy for the transitioning category presumably stemmed from insufficient

22 frequency of the image acquisition which can be readily improved. Hence the reported system 
provides an effective way to automatically process and classify the sow's behavioral images. This tool is conducive to investigating behavioral responses and time budget of lactating sows and their litters to farrowing crate designs and management practices.

Keywords: Animal welfare, depth image, image processing, sow behaviors

\section{Introduction}

Animal behaviors are reflective of its welfare/well-being state. They contain important information that can enable producers to better manage livestock (Brown-Brandl et al., 2013). For instance, research has shown that changes in feeding behavior can occur in response to thermal conditions of growing-finishing swine (Nienaber and Hahn, 2000), health status of sow and feedlot cattle (Cornou et al., 2008; Griffin, 2001), and diet of dairy goats (Adijaoude et al., 2000). Drinking behavior of pigs can be indicative of disease outbreak such as intestinal disorders (Kashiha et al., 2013; Madsen and Kristensen, 2005) and indoor climatic conditions (Bird and Crabtree, 2000). Lying or moving behaviors of lactating sows influence the livability of piglets (Valros et al., 2003; Mainau et al., 2008; Valros et al., 2006). Activity levels indicate the health and welfare of broiler chickens (Aydin et al., 2010); and they may also be used as an index of the thermal comfort for pigs (Anderson et al., 2008).

Traditional manual observation of real-time or recorded animal behaviors is laborious, subjective, inefficient, expensive, limited in the amount of data, and prone to human errors. Many sensors and sensing techniques are available or under development to increase the ability of automating measurements of animal behavioral and biological responses. Nowadays, image analysis (Ahrendt et al., 2011), sound analysis (Guarino, 2008) and other electronic sensors such as RFID (Brown-Brandl et al., 2013) are increasingly finding their use in animal production.

Digital image analysis is a common method used to automatically monitor animal 
behaviors and welfare (Shao and Xin, 2008; Kristensen and Cornou, 2011; Lao et al., 2012). It focuses on the animal's horizontal distribution attributes. Analysis of digital images obtained from video-recordings is an effective tool for studying livestock behaviors under various environmental conditions (Porto et al., 2013). During digital image processing, image segmentation and feature extraction are the most important steps among the image analysis methods considered. Digital image analysis methods can work well under the following conditions: the animal images have a high contrast with the background to allow for image segmentation; the background is constant or has constant brightness variations to extract the animal features from the image; the color range applied to the animal is different from the background (Porto et al., 2013). However, image segmentation in digital RGB image can be problematic under real farm conditions due to dynamic background restrictions, such as dim or uneven light intensity of the house and varying floor status. These factors can affect the robustness of the algorithm for accurate classification.

To improve the ability of attending farrowing and piglet livability, Cornou and Kristensen (2014) researched a method to monitor sow's activity before, during and after farrowing through analysis of recorded video. By means of image processing, Viazzi et al. (2014) developed continuous automated detection of aggressive interactions among pigs and achieved an 89\% detection accuracy. Applying a multi-process Kalman filter, Cornou and Lundbye-Christensen (2010) reported a 64\% average recognition rate for passive (lying laterally or sternally) and active (feeding, rooting, and walking) behaviors of sows. Escalante et al. (2013) employed a supervised machine learning approach to classify sow activities recorded with accelerometers and achieved an average recognition rate of $74.6 \%$. Oczak et al. (2015) used accelerometer data to classify nest-building behaviors of non-crated farrowing sows and obtained $86 \%$ accuracy. Information captured by a depth image sensor differs considerably from that of color 
digital images in that each pixel in the depth data reflects the distance between the object and the depth image sensor. Depth image analysis is a new method that helps detecting not only horizontal but also vertical distribution attributes of the animal (Gregersen et al., 2013) without the restriction of light conditions. This feature allows for continuous monitoring of the animal behaviors throughout the day. Depth image analysis has been used in automatic detection of animal lameness (Van Hertem et al., 2013; Viazzi et al., 2013).

A review of literature did not find application of depth image analysis to automatically recognize behaviors of lactating sows in farrowing crates. Such an automatic analytical tool would greatly enhance researchers' ability to evaluate and optimize the design of swine farrowing facilities based on behavioral responses of the animals, which will lead to improved animal well-being and production performance. Therefore, the objective of the study was to develop and evaluate a depth image-based machine vision system that automatically recognizes the behaviors of lactating sows and their litters in farrowing crates. The system will be subsequently used to quantify behavioral responses and time budget of sows and litters as affected by farrowing facility design and management practices.

\section{Material and Methods}

\section{$\underline{2.1 \text { Animals and data collection }}$}

Three farrowing crates were selected at the swine research facility of the USDA-ARS Meat Animal Research Center, Clay Center, Nebraska, USA. The farrowing crates each housed one Landrace sow and her litter, from 4 to 19 days of age during the monitoring period. Each farrowing crate had the dimension of $1.5 \mathrm{~m} \mathrm{~W} \times 2.1 \mathrm{~m} \mathrm{~L}$ with $0.6 \mathrm{~m}$ wide sow area and two 0.45

$\mathrm{m}$ wide piglets creep areas. Room temperature was kept at approximately $22^{\circ} \mathrm{C}$. One heat lamp $(175 \mathrm{~W})$ was suspended above the creep area to the sow's left side. 

Images were collected for 16 days, 24 hours per monitoring day. A top-view 3D Kinect camera for Windows V1 (Microsoft Corp., Washington, USA) was used to monitor the farrowing crate (Figure 1). The camera was installed $2.20 \mathrm{~m}$ above the crate floor and captured digital images in JPEG format (used for manual verification) and depth images in text format (used for automatic recognition and manual verification). Both types of images had a resolution of $640 \times 480$ pixels (Jana, 2012). The Kinect camera was connected via a USB port to a computer that stored the digital and depth images for subsequent analysis. The images were recorded at approximately $6 \mathrm{~s}$ intervals.

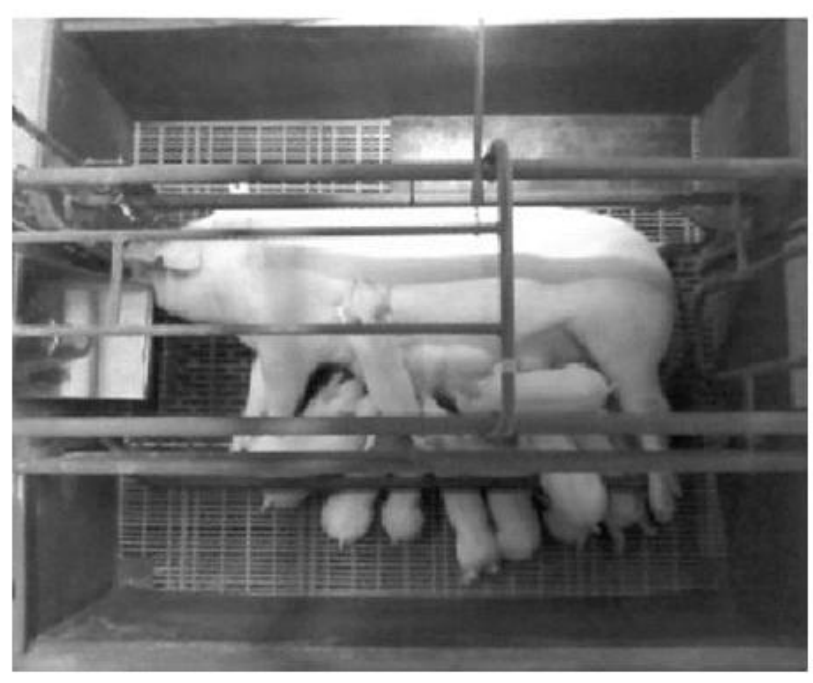

a

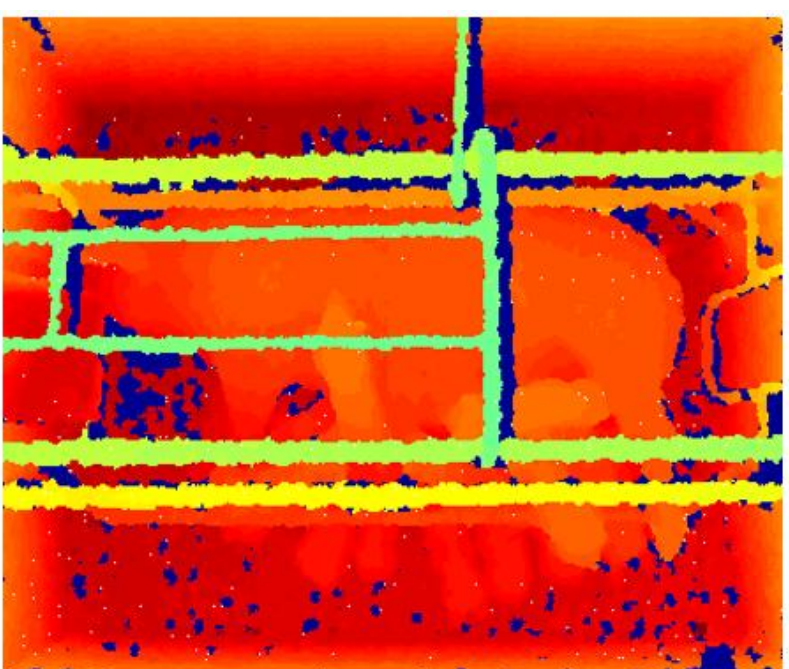

b

Figure 1. Example of a) digital image and b) raw depth image of a lactating sow and litter in a farrowing crate.

\subsection{Image processing principle and algorithm}

Our image-processing and analysis algorithm was developed using the MATLAB R2013b software. The algorithm identified the sow's behaviors based on the pre-processed depth image data, and the manual verification was based on both the digital image and the depth image data. By comparing the behavioral recognition results between the algorithm analysis and the manual 
observation, accuracy of the automatic identification was determined.

2.2.1 Depth image processing

The sow behavior recognition algorithm was based on the average distance from several parts of the sow's body to the floor of the farrowing crate, along with a few attributes of the sow's body (centroid coordinates) and the farrowing crate profile (feeder and drinker positions). To obtain the average distances, the raw depth image data need to be processed first, which included the following steps and procedures.

a. The Kinect sensor returned 16-bit raw depth frame data, with the first 3 bits representing the identification of the object and the remaining upper 13 bits providing the measured distance between the subject pixel and the Kinect sensor in mm (Jana, 2012). To change the raw depth data to real (physical) depth data, i.e., distance between each point of the sow and the floor, a 3-bit shift operation (i.e., dividing the 16-bit value by 8) was performed, followed by subtraction, as shown in equations (1) and (2). The new depth data were further processed following steps b) to f) below to obtain the necessary feature values for identification of the sow's behaviors.

$$
\begin{aligned}
& \text { height }_{\text {output }}(\mathrm{cm})=\frac{1}{8} \times(\text { raw depth data }) \times \frac{1 \mathrm{~cm}}{10 \mathrm{~mm}} \\
& \text { New depth data }(\mathrm{cm})=\text { height }_{\text {kinect }}-\text { height }_{\text {output }}
\end{aligned}
$$

where height $t_{\text {kinect }}$ is the height of the kinect camera sensor above the floor in $\mathrm{cm}$.

Note that the raw depth data were in $\mathrm{mm}$, while the new depth data were in $\mathrm{cm}$.

b. Set high $(>90 \mathrm{~cm})$ and low $(<6 \mathrm{~cm})$ threshold values and four sides of the farrowing crates to 0 to reduce noise effect and speed up the processing.

c. Remove the feeder and crate frame pipes, then reconstruct the sow areas blocked by the 
pipes through line refilling.

d. Apply moving average filter to fill the small holes in the depth image of the sow to obtain a clear version of the sow's depth image.

e. Change the depth image to a binary image to extract certain important features, including the sow's centroid coordinates ( $\left.x_{\text {centroid }}, y_{\text {centroid }}\right)$, leftmost and rightmost pixels as the head pixel and hip pixel, respectively; then calculate the x-coordinate of midpoint pixels between the head and the centroid, between the centroid and the rear to yield four $\mathrm{x}$ coordinates $-x_{\text {head }}, x_{\text {hip }}, \quad x_{\text {shoulder }}$, and $x_{\text {loin }}$, respectively.

f. Divide the sow in the depth image into 7 parts (all, upper half, lower half, head, shoulder, loin and hip), as shown in Figure 2. A horizontal line $y=y_{\text {centroid }}$ passing through the sow's centroid was drawn to divide the upper and lower parts of the sow, and the other four parts were divided by three vertical lines of $x=x_{\text {shoulder }}, x=x_{\text {centroid, }}$ and $x=$ $x_{\text {hip }}$

g. Calculate the average value of all the depth pixels of each sow's part, designated as $d_{\text {all }}, d_{\text {upper }}, d_{\text {lower }}, d_{\text {head }}, d_{\text {shoulder }}, d_{\text {loin }}$, and $d_{\text {hip }}$, respectively.

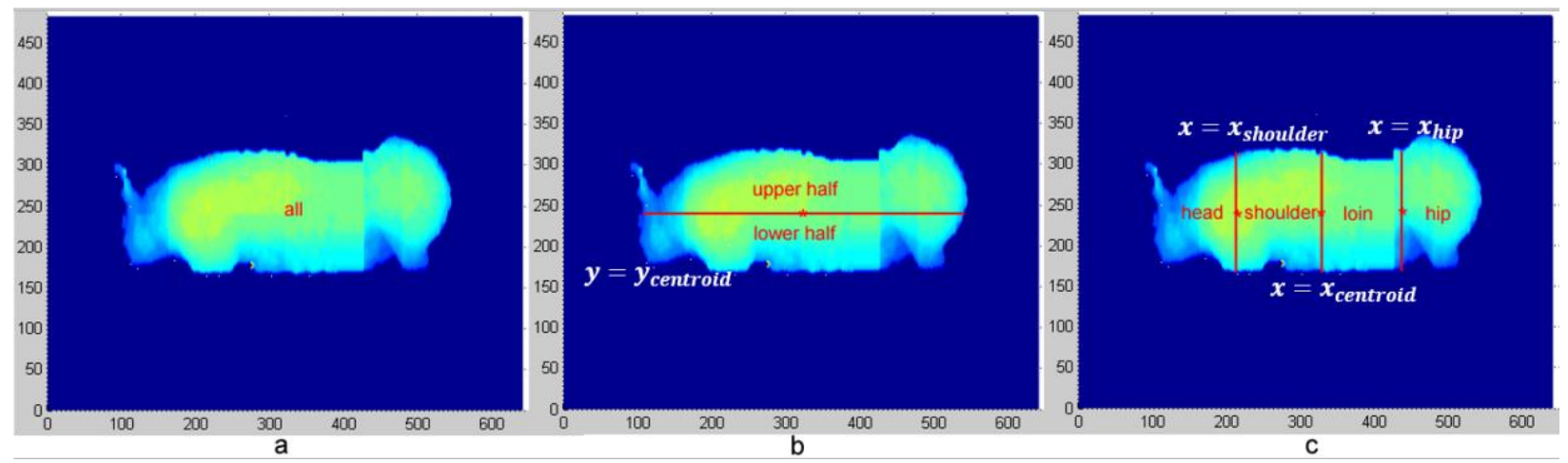

Figure 2.Definitions of seven parts of the sow in the depth image: a) all, b) upper and lower half, and c) head, shoulder, loin, and hip; and $x$ and $y$ coordinates for the positions. 


\begin{tabular}{|c|c|}
\hline Definition & Description \\
\hline Lying $^{\mathrm{a}}$ & $\begin{array}{l}\text { Resting with her side in contact with the farrowing crate floor. In this study lying was further } \\
\text { divided as either her backside facing the heat lamp ("backside facing heat lamp") or her udders } \\
\text { facing the heat lamp ("udders facing heat lamp") }\end{array}$ \\
\hline Sitting $^{\mathrm{a}}$ & Sitting on her hip. Two types: sitting only, and sitting and drinking \\
\hline Standing $^{\mathrm{a}}$ & Standing still or walking. Three types: exploring, standing and feeding, and standing and drinking \\
\hline Kneeling $^{\mathrm{a}}$ & The front legs are kneeling on the floor and the behind legs are standing \\
\hline Feeding $^{\mathrm{b}}$ & Head in the feeder with up and down movement \\
\hline Drinking $^{\mathrm{b}}$ & Mouth on nipple drinker \\
\hline Moving $^{\mathrm{c}}$ & The Eulerian distance of the sow's centroid between two consecutive depth images \\
\hline Shifting $^{c}$ & Transitioning from one behavior to another \\
\hline Behaviors th & clusively. \\
\hline${ }^{\mathrm{b}}$ Behaviors th & hen the sow is engaged in one of the exclusively occurring behaviors. \\
\hline
\end{tabular}

\subsubsection{Definition of the sow behaviors}

The sow's behaviors covered in this analysis included lying, sitting, standing, kneeling, feeding, drinking, transitioning or shifting from one behavior to another, and moving. The definitions and description of the behaviors (Beirendonck et al., 2014; Johnson et al., 2001) are listed in Table 1.

Table 1. Definition and description of sow behaviors in a farrowing crate 
162

corresponding digital image to a new image, which makes the subsequent manual recognition/validation more convenient.

Part 2 involves the following steps to recognize the sow's behaviors automatically. It should be noted that values $\mathrm{V}_{1}$ to $\mathrm{V}_{9}$ used in the algorithm will vary slightly with the camera's height and resolution, the nipple drinker's position and height, and the feeder's position and size. In this paper, these values were acquired by statistical analysis of half-day worth of processed depth images, and are defined as follows.

$\mathrm{V}_{1}=$ the height of nipple drinker, $\left(\mathrm{V}_{1}=50 \mathrm{~cm}\right)$

$\mathrm{V}_{2}=$ one third of the nipple drinker area, $\left(\mathrm{V}_{2}=500\right.$ pixels $)$

$\mathrm{V}_{3}=$ portion of the feeder area, $\left(\mathrm{V}_{3}=700\right.$ pixels which corresponds to $12 \%$ of the feeder area)

$\mathrm{V}_{4}=$ average of $\mathrm{d}_{\text {all }}$ in lying $+\left(\right.$ average of $\mathrm{d}_{\text {all }}$ in kneeling - average of $\mathrm{d}_{\text {all }}$ in lying $) / 2,\left(\mathrm{~V}_{4}=31\right.$

$\mathrm{cm})$

$\mathrm{V}_{5}=$ average of $\mathrm{d}_{\text {all }}$ in standing, $\left(\mathrm{V}_{5}=64 \mathrm{~cm}\right)$

$\mathrm{V}_{6}=$ minimum value of $x_{\text {head }}$ when feeding, $\left(\mathrm{V}_{6}=9\right.$ pixels $)$

$V_{7}=$ average of $d_{\text {shoulder }}$ when sitting, $\left(V_{7}=60 \mathrm{~cm}\right)$

$\mathrm{V}_{8}=$ the maximal $\mathrm{x}$-coordinate value of the feeder, $\left(\mathrm{V}_{8}=47\right.$ pixels $)$

$\mathrm{V}_{9}=$ average of $\mathrm{d}_{\text {shoulder }}$ in standing, $\left(\mathrm{V}_{9}=70 \mathrm{~cm}\right)$

a. Determine drinking behavior that may happen concurrently with other behaviors such as standing, sitting or lying. Searching the sow pixels connected to or near the nipple drinker in horizontal distribution and their height greater than the height of the nipple drinker $\left(\mathrm{V}_{1}\right)$. If the result is greater than one third of the nipple drinker area $\left(\mathrm{V}_{2}\right)$ the sow is likely drinking. Due to the proximity between the feeder and the nipple drinker, in some cases when the sow 
was feeding her body might also seem to touch the nipple drinker. To distinguish this from true nipple drinker contact the following condition was added: if her pixels in the feeder area are less than $12 \%$ of the feeder area $\left(\mathrm{V}_{3}\right)$ the sow is judged to be drinking and the flag "drinkflag" is set to 1 , else it is set to 0 .

b. Apply $d_{\text {all }}, d_{\text {upper }}$ and $d_{\text {lower }}$ as the lying-posture classification criteria. If $d_{a l l}<V_{4}$, the sow is classified as in lying posture. Once the sow is determined to be in her lying posture, another step combined with the drinkflag is used to further classify the sow's lying posture into "udders facing heap lamp", "udders facing heap lamp and drinking”, "backside facing heat lamp" or "backside facing heat lamp and drinking". A separate paper will report this aspect of the sow's behavior and the associated behaviors of the piglets. When examining the depth image of lying sow (Figure 2) we can see that the udders side has a lower depth to the floor than the backside. In this study the heat lamp was located above the "upper part" of the image. Hence when $d_{\text {upper }}$ is smaller than $d_{\text {lower }}$ it means the sow taking the posture of lying with "udders facing heap lamp". Conversely, when the $d_{\text {upper }}$ is larger than $d_{\text {lower }}$ it means that the sow taking the posture of lying with "backside facing heat lamp".

c. If the sow is not in lying posture, $d_{\text {all }}, d_{\text {head }}, d_{\text {hip }}, d_{\text {shoulder }}, d_{\text {loin }}$ and $x_{\text {head }}$ combined with drinking recognition are used to classify the sow into "sitting", "sitting and drinking", "kneeling", "standing and feeding", "standing and exploring”, or "standing and drinking". If $\mathrm{d}_{\text {all }}<\mathrm{V}_{5}, \mathrm{x}_{\text {head }}>\mathrm{V}_{6}$ and $\mathrm{d}_{\text {hip }}<\mathrm{d}_{\text {shoulder }}$ then the sow is sitting; if $\mathrm{d}_{\text {all }}<\mathrm{V}_{5}, \mathrm{~d}_{\text {shoulder }}<\mathrm{d}_{\text {loin, }}$, and $\mathrm{d}_{\text {shoulder }}<\mathrm{V}_{7}$ then the sow is kneeling; otherwise the sow is standing. When the sow is standing, the following rules are used to determine her standing type: if the sow's head is above the feeder $\left(\mathrm{x}_{\text {head }}<\mathrm{V}_{8}\right)$ and lowering her head to the feeder $\left(\mathrm{d}_{\text {head }}<\mathrm{V}_{9}\right)$ it means she is feeding, otherwise she is merely standing or standing and drinking.

In part 3, shifting or movement is judged by comparing the behaviors between the current 
and the previous depth images. If the two behaviors are different, it means that shifting has occurred and the sow has changed her behavior. Movement is acquired by computing the change in the centroid location between the current and the previous depth images, namely,

$$
\text { Movement }=\sqrt{\left(x_{\text {centroid } 1}-x_{\text {centroid } 2}\right)^{2}+\left(y_{\text {centroid } 1}-y_{\text {centroid } 2}\right)^{2}} \text {. }
$$

where centroid 1 and centroid 2 stand for the sow's centroid in the respective image.

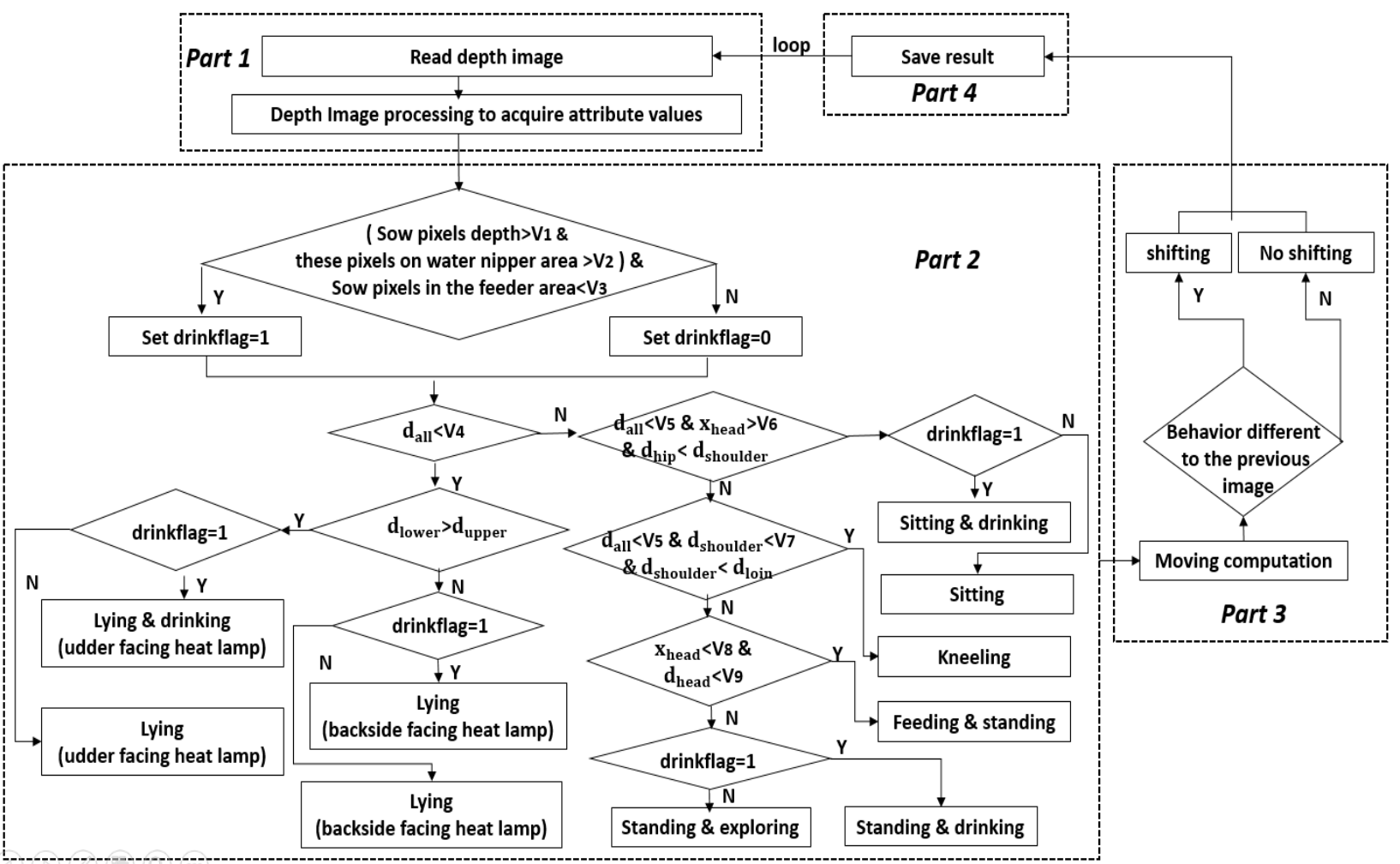

Figure 3. Image processing and analysis processes for recognition of the sow behaviors.

A total of 43,380 depth images and the same number of digital images were used to evaluate the performance of the recognition algorithm. The images were recorded from three farrowing crates over three days at 6 s intervals when the piglets were 5, 11, and 18 days of age. The accuracy of behavioral classification is computed by the following equations. 


$$
P_{F P R}=\frac{\text { Number of other postures classifed as the defined posture }}{\text { Total number of the defined behavior occurences to be classified }}
$$

$$
P_{F N R}=\frac{\text { Number of defined posture classified as other postures }}{\text { Total number of the defined behavior occurences to be classified }}
$$

223 where $\mathrm{P}_{\mathrm{FPR}}$ is the rate of misclassifying other behaviors as the true behavior (i.e., false positive),

224 whereas $\mathrm{P}_{\mathrm{FNR}}$ is the rate of misclassifying the true behavior as other behaviors (i.e., false 225 negative). 


\section{Results and Discussion}

The accuracies of the behavioral classifications by the image processing and analysis algorithm, relative to manual recognition, are presented in Tables 2 to 4 . As shown by the data in Table 2, out of the 36,419 lying images, 36,382 were correctly identified or at a $99.9 \%$ accuracy, with 2 false positives ( 1 kneeling and 1 sitting postures) and 37 false negatives (31 as sitting, 5 as standing, and 1 as kneeling). Out of the 1,818 total sitting events, the algorithm correctly recognized 1,775 or at a $96.4 \%$ accuracy. Specifically, the algorithm incorrectly recognized 31 lying and 12 standing as sitting, resulting in a classification error $\mathrm{P}_{\mathrm{FPR}}$ of $2.37 \%$. In addition, 1 , 19 and 2 of the 1,797 sitting behaviors were incorrectly classified as lying, standing and kneeling, respectively, yielding a classification error $\mathrm{P}_{\mathrm{FNR}}$ of $1.22 \%$. Similarly, classification accuracy for standing and kneeling was $99.2 \%$, and $78.1 \%$, respectively. The overall classification accuracy of lying, sitting, standing and kneeling was $99.8 \%$. The relatively lower classification accuracy for kneeling was caused by misclassification when the sow was sitting or standing with her neck or head lowered. The results also showed that over the three monitoring days the sows spent 84.0 $( \pm 0.9) \%$ of time lying down, $4.1( \pm 0.8) \%$ of time sitting, $11.8( \pm 0.6) \%$ of time standing. The $84 \%$ lying time for the sows paralleled the literature report that pigs spend $75 \%-80 \%$ of their time lying down (Velarde and Geers, 2007; Rolandsdotter et al., 2009; Whittaker et al., 1999).

Table 2. Classification rate of sow's lying, sitting, standing, and kneeling behaviors by the image analysis algorithm, calculated as $P_{\text {accuracy }}=1-P_{F P R}-P_{F N R}$

\begin{tabular}{ccccccc}
\hline \multirow{2}{*}{ Behavior } & \multicolumn{7}{c}{ Classified by the algorithm as } \\
\cline { 2 - 7 } & Lying & Sitting & Standing & Kneeling & Total & Accuracy \\
\hline Lying & 36,382 & 1 & 0 & 1 & 36,384 & $99.9 \%$ \\
\hline Sitting & 31 & 1,775 & 12 & 0 & 1,818 & $96.4 \%$ \\
\hline Standing & 5 & 19 & 5,117 & 0 & 5,141 & $99.2 \%$ \\
\hline Kneeling & 1 & 2 & 3 & 31 & 37 & $78.1 \%$ \\
\hline Total & 36,419 & 1,797 & 5,132 & 32 & 43,380 & $99.8 \%$ \\
\hline
\end{tabular}


The identified lying behaviors were further analyzed by comparing the average heights of upper and lower parts of the image to distinguish between the two lying orientations. For the 36,382 correctly recognized lying images, only three were incorrectly recognized between "backside facing heat lamp" and "udders facing heat lamp" orientations. The reason was that sometimes the piglets climbed on the sow's udder side which occasionally caused the height of the udder side greater than the backside, as shown in Figure 4. The result suggests that the rule of comparing the average heights of the upper and lower parts of the sow to distinguish between back and udder sides worked well.
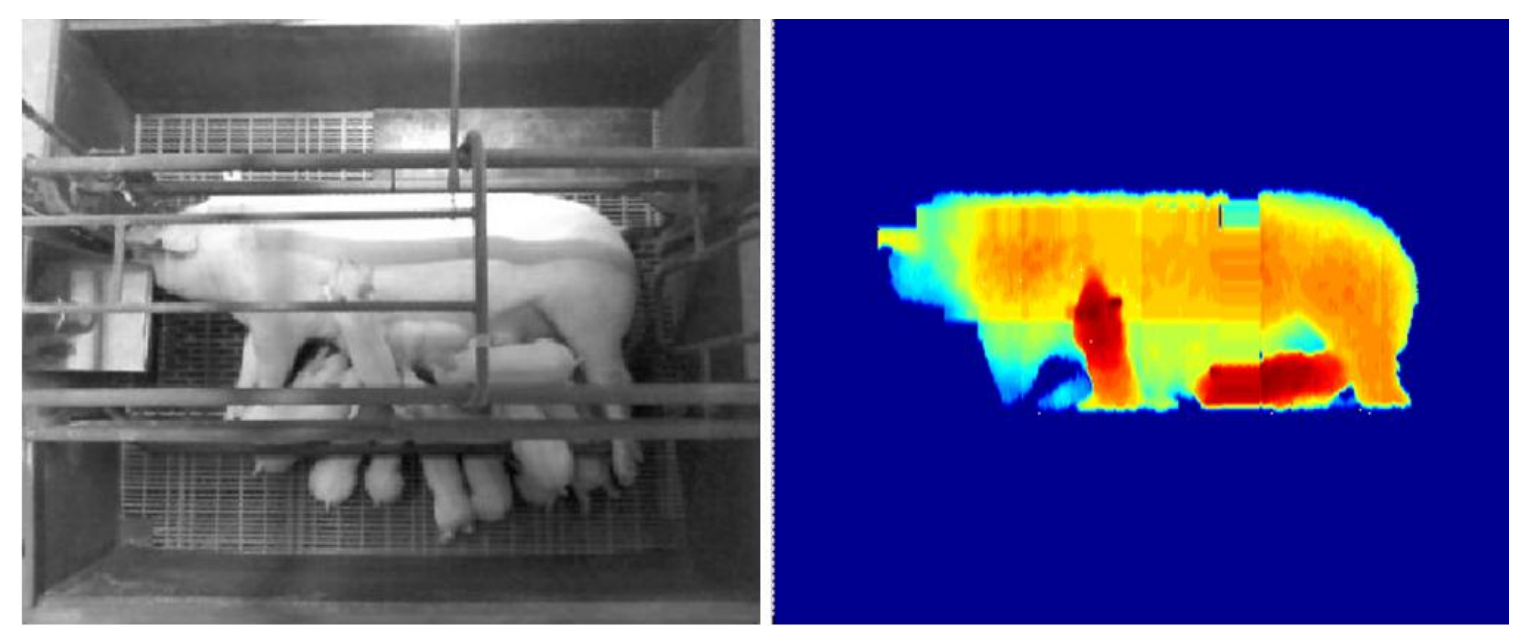

Figure 4. Piglets on the sow's udder side could lead to incorrectly recognized lying orientation.

As shown by the data in Table 3, a total of 4,038 feeding images were correctly classified and four were misclassified as others, but 102 other images were misclassified as feeding behavior, yielding a classification accuracy of $97.4 \%$. For the drinking behavior, the algorithm correctly classified 1,139 out of 1,207 and incorrectly classified 16; it also misclassified 68 other behaviors as drinking, yielding a $92.7 \%$ classification accuracy. The lowest accuracy was associated with the shifting classification (63.9\%). This outcome was partially attributable to the fact that when one image was misclassified it often resulted in two shifting errors. For example, 
if the second image of 3 consecutive standing images was recognized as sitting it would lead to two shifting classification errors: images 1 to 2 as "standing to sitting" and images 2 to 3 as "sitting to standing". The primary cause is believed to be insufficient image sampling frequency, which missed some of the transitioning dynamics. This drawback, however, can be easily corrected in future studies.

Table 3. Classification rate of sow's feeding, drinking and shifting behaviors (a total of 43,380 images)

\begin{tabular}{lcccc}
\hline \multirow{2}{*}{ Posture } & Manual & \multicolumn{2}{c}{ Image algorithm analysis } & \multirow{2}{*}{ Rate of accuracy } \\
\cline { 3 - 4 } & recognition & True positives & False positives & \\
\hline Feeding & 4,042 & $4,038(99.9 \%)$ & $102(2.52 \%)$ & $97.4 \%$ \\
\hline Drinking & 1,155 & $1,139(98.6 \%)$ & $68(5.89 \%)$ & $92.7 \%$ \\
\hline Shifting & 249 & $243(97.6 \%)$ & $84(33.73 \%)$ & $63.9 \%$ \\
\hline
\end{tabular}

Table 4 further summarizes the distribution of sow's sitting, standing, feeding and drinking behaviors over the three monitoring days. On average the sows spent $43.6 \%$ of sitting time drinking, $78.8 \%$ of standing time feeding, and $15.4 \%$ of standing time exploring. It can also be noted that the sows tended to drink more while sitting $(67.8 \%)$ than while standing $(25.7 \%)$ or lying $(6.4 \%)$.

Table 4. Distribution of a sow's sitting, standing, feeding and drinking behavioral events and the relative percentages (mean \pm SD) over three days of monitoring

\begin{tabular}{lcccccc}
\hline From/To & $\begin{array}{c}\text { Sitting } \\
\text { only }\end{array}$ & $\begin{array}{c}\text { Sitting \& } \\
\text { drinking }\end{array}$ & $\begin{array}{c}\text { Standing \& } \\
\text { exploring }\end{array}$ & $\begin{array}{c}\text { Standing \& } \\
\text { drinking }\end{array}$ & $\begin{array}{c}\text { Standing \& } \\
\text { feeding }\end{array}$ & $\begin{array}{c}\text { Lying \& } \\
\text { drinking }\end{array}$ \\
\hline Sitting & 338 & 261 & $*$ & $*$ & $*$ & $*$ \\
\hline Standing & $*$ & $*$ & 264 & $99(5.8 \pm 2.0 \%)$ & $1347(78.8 \pm 12.8 \%)$ & $*$ \\
\hline Drinking & $*$ & 261 & $*$ & 99 & $*$ & 25 \\
\hline
\end{tabular}

Figure 5 depicts the movement of centroid of a sow during three monitoring days. Figure 6 depicts diurnal hourly movements of the sow. From Figure 6 it can be seen that the sow tended 
to be more active during the period of $02: 00$ to $12: 00 \mathrm{~h}$ than the rest of the day. The sow also

280 showed increased activity levels as the piglets grew. This outcome presumably resulted from the

281 sow needing to increase feed intake to meet the increasing milk demand by the growing piglets.

282 In fact, the sow's lying time changed slightly from $84.7 \%$ when the piglets were 5 days old to

$28383.0 \%$ when the piglets were 18 days old; but the sow's daily feeding time increased from 136

$284 \min$ to 174 min during the same period.

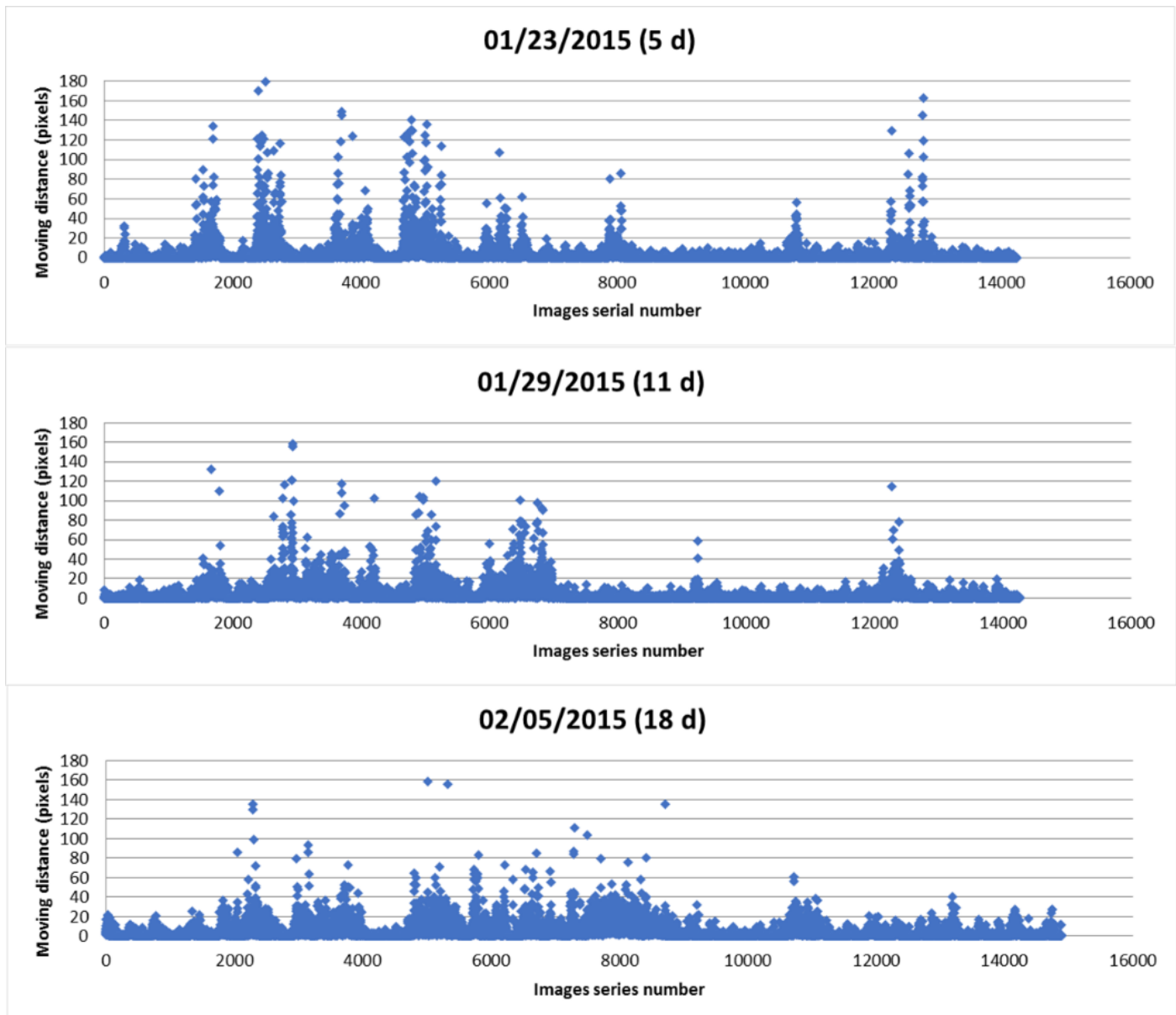

Figure 5. Movement of a sow's centroid on $5^{\text {th }}, 11^{\text {th }}$ and $18^{\text {th }}$ day of lactation. 

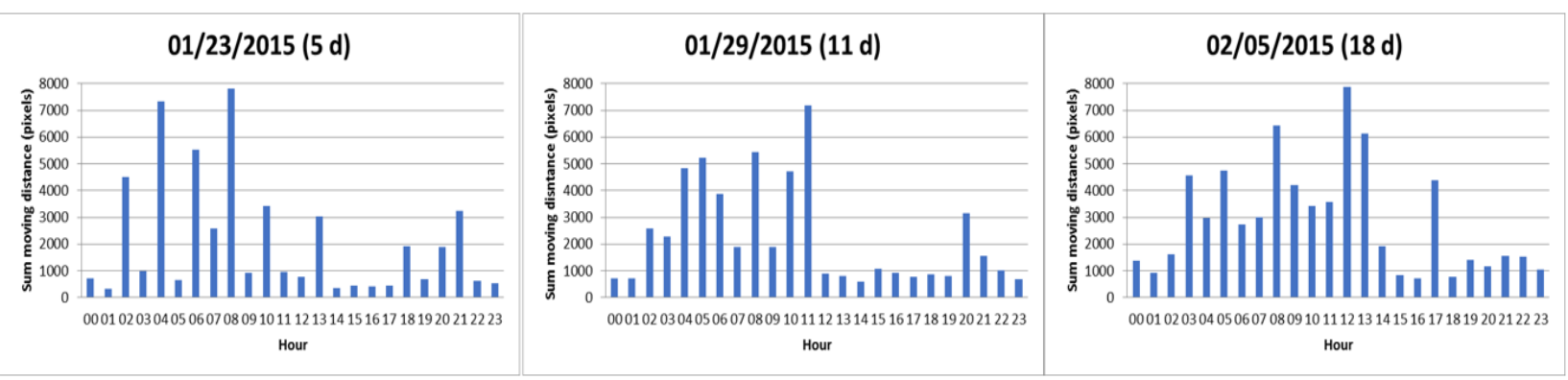

Figure 6. Diurnal hourly movements of a sow's centroid on three lactating days.

\section{Conclusions}

An algorithm was developed and applied that automatically processes and analyzes depth images of sow's lying, sitting, standing, kneeling, feeding, drinking, shifting and moving behaviors in farrowing crates. Classification of the sow behaviors with the algorithm demonstrated high degrees of accuracy. Data from limited number of animals confirm that the sow spends a much greater amount of time lying (84.0\%) as compared to sitting (4.1\%) and standing (11.8\%). The sow's moving activity increased with increasing piglet age. Future work should increase the frequency of depth image acquisition in order to better capture and quantify the sow's behavioral transitioning and the associated implications in animal health and adequacy of facility design. Information of this nature is expected to provide insight for improved design and management of swine farrowing facility and operation, which will ultimately enhance animal welfare and improve the efficiency of resource utilization.

\section{Acknowledgements}

This study was funded in part by the College of Agriculture and Life Sciences at Iowa State University, USDA-ARS Meat Animal Research Center, the "Twelfth Five-Year-Plan" for National Science and Technology for Rural Development in China (2014BAD08B05-01-01), and the China Scholarship Council. Special thanks go to the staff of the USDA Meat Animal Research Center for their assistance in data collection and animal care. 


\section{References}

Adijaoude, J.A., Morand-Fehr, P., Tessier, J., Schmidely, P.H., Sauvant, D., 2000. Diet effect on the daily feeding behaviour, frequency and characteristics of meals in dairy goats. Livestock Production Science. 64(1):29-37.

Ahrendt, P., Gregersen, T., Karstoft H., 2011. Development of a real-time computer vision system for tracking loose-housed pigs. Computers and Electronics in Agriculture. 76(2):169-174.

Andersen, H.M.-L., Jørgensen, E., Dybkjær, L., Jørgensen, B., 2008. The ear skin temperature as an indicator of the thermal comfort of pigs. Applied Animal Behaviour Science. 113 (1-3): 43-56

Aydin, A., Cangar, O., Eren Ozcan, S., Berckmans, D., 2010. Application of a fully automatic analysis tool to assess the activity of broiler chickens with different gait scores. Computers and Electronics in Agriculture. 73(2):194-199.

Bahr, C., Berckmans, D., 2014. Image feature extraction for classification of aggressive interactions among pigs. Computers and Electronics in Agriculture. 104:57-62.

Beirendonck, S., Thielen, J., Verbeke, G., Driessen, B., 2014. The association between sow and piglet behavior. Journal of Veterinary behavior. 9:107-113.

Bird, N. and Crabtree, H., 2000. Real-time production performance monitoring. Pig Journal. 45, 55-68.

Brown-Brandl, T.M., Rohrer G.A., Eigenberg, R.A., 2013. Analysis of feeding behavior of group housed growing-finishing pigs. Computers and Electronics in Agriculture. 96:246-252.

Cornou, C., Kristensen, A., 2014. Monitoring individual activity before, during and after parturition using sensors for sows with and without straw amendment. Livestock Science. 168:139-148.

Cornou, C., Lundbye-Christensen, S., 2010. Classification of sows' activity types from acceleration patterns using univariate and multivariate models. Computers and Electronics in Agriculture. 72:5360.

Cornou, C., Vinther, J., Kristensen, A., 2008. Automatic detection of oestrus and health disorders using data from electronic sow feeders. Livestock Science. 118 (3):262-271.Escalante, H.J., Rodriguez, S.V., Cordero, J., Kristensen, A.R., Cornou, C., 2013. Sow-activity classification from acceleration patterns: A machine learning approach. Computers and Electronics in Agriculture. 93:17-26. 
Jana, A., 2012. Kinect for Windows SDK programming guide. Packt Publishing Ltd., Birminghan, pp. $122-126$.

Lao, F., Teng, G., Li, J., Yu, L., Li, Z., 2012. Behavior recognition method for individual laying hen based on computer vision. Transactions of the Chinese Society of Agricultural Engineering. 28(24):157-163.

Gregersen, T., Jensen, T., Andersen, M., Mortensen, L., Maselyne, J., Hessel, E., Ahrendt, P., 2013. Consumer grade range cameras for monitoring pig feeding behaviour. In: $6^{\text {th }}$ European Conference on Precision Livestock Farming, 2013, pp. 360-369.

Griffin, D., 2001. How health status and environment influence the feeding behavior of feedlot cattle. In: 3rd Annual Intermountain Nutrition Conference, Utah State University, Logan, Utah, 117-124.

Guarino, M., Jans, P., Costa, A., Aerts, J.-M., Berckmans, D., 2008. Field test of algorithm for automatic cough detection in pig houses. Computers and Electronics in Agriculture. 62(1):22-28.

Jana, A., 2012. Kinect for windows SDK programming guid. Packt Publishing Ltd., Birminghan, pp. $122-138$.

Johnson, A., Morrow-Tesch, J., McGlone, J., 2001. Behavior and performance of lactating sows and piglets reared indoors or outdoors. Journal of Animal Science. 79:2571-2579.

Kashiha, M., Bahr, C., Haredasht, S.A., Ott, S., Moons, C.P., Niewold, T.A., Ödberg, F.O., Berckmans, D., 2013. The automatic monitoring of pigs water use by cameras. Computers and Electronics in Agriculture. 90:164-169.

Kristensen, H. H. and Cornou, C., 2011. Automatic detection of deviations in activity levels in groups of broiler chickens - A pilot study. Biosystems Engineering. 109(4):369-376.

Madsen, T.N. and Kristensen, A.R., 2005. A model for monitoring the condition of young pigs by their drinking behaviour. Computers and Electronics in Agriculture. 48 (2):138-154.

Mainau, E., Dalmau, A., de-la Torre, J.R., Manteca, X., 2009. Validation of an automatic system to detect position changes in puerperal sows. Applied Animal Behaviour Science. 121(2):96-102

Nienaber, J.A., and Hahn, G.L., 2000. Feeding behavior and energetics of growing-finishing swine as influenced by environmental temperature. ASABE meeting paper No. 87-4512. American society of 
agricultural engineers, St. Joseph, MI 49085.

Oczak, M., Maschat, K., Berckmans, D., Vranken, E., Baumgartner, J., 2015. Classification of nestbuilding behaviour in non-crated farrowing sows on the basis of accelerometer data. Biosystems engineering. 140, 48-58.

Rolandsdotter, E., Westin, R. and Algers, B., 2009. Maximum lying bout duration affects the occurrence of shoulder lesions in sows. Acta Veterinaria Scandinavica. 51(44):1-7.

Shao, B. and Xin, H., 2008. A real-time computer vision assessment and control of thermal comfort for group-housed pigs. Computers and Electronics in Agriculture. 62(1):15-21.

Porto, S.M.C., Arcidiacono, C., Anguzza, U., Cascone, G., 2013. A computer vision-based system for the automatic detection of lying behaviour of dairy cows in free-stall barns. Biosystems Engineering. 115(2):184-194.

Valros, A., Rundgren, M., Špinka, M., Saloniemi, H., Algers, B., 2006. Sow activity level, frequency of standing-to-lying posture changes and anti-crushing behaviour-within sow-repeatability and interactions with nursing behaviour and piglet performance. Applied animal behaviour 83(1): 29-40.

Van Hertem, T., Maltz, E., Antler, A., Alchanatis, V., Schlageter-Tello, A., Lokhorst, C., Romanini, C.E.B., Viazzi, S., Bahr, C., Berckmans, D., Halachmi, I., 2013. Automatic lameness detection based on 3D-video recordings. In: 6th European Coference on Precision Livestock Farming, 2013, pp. 5967.

Velarde, A. and Geers, R., 2007. On farm monitoring of pig welfare. Wageningen Academic Publisher, Wageningen, pp 19-23.

Viazzi, S., Ismayilova, G., Oczak, M., Sonoda, L.T., Fels, M., Guarino, M., Vranken, E., Hartung, J., Bahr, C., Berckmans, D., 2014. Image feature extraction for classification of aggressive interactions among pigs. Computers and Electronics in Agriculture. 104:57-62.

Viazzi, S., Van Hertem, T., Romanini, C.E.B., Bahr, C., Halachmi, I., Schlageter Tello, A., Lokhorst, C., Rozen, D., Berckmans, D., 2013. Automatic back posture evaluation in dairy cows using a 3D camera. In: $6^{\text {th }}$ European Conference on Precision Livestock Farming, 2013, pp. 83-91.

Whittaker, X., Edwards, S.A., Spoolder, H.A.M., Lawrence, A.B., Corning S., 1999. Effects of straw 

Behaviour Science. 63(1), 25-39. 